\title{
VIENTOS DE RESISTENCIA: MOVIMIENTOS INDÍGENAS Y PARQUES EÓLICOS EN EL ISTMO DE TEHUNTEPEC (OAXACA, MÉXICO)
}

\section{Águeda Gómez Suárez}

Universidad de Vigo

Miguel Martínez González

Universidad del Mar, México

https://doi.org/10.33676/EMUI_nomads.55.07

Resumen: Desde inicios del año 2000, en que comenzó el desarrollo e implantación de proyectos eólicos en el Istmo de Tehuantepec (Oaxaca, México), los pueblos indígenas zapotecos e ikoots de la región se han movilizado para hacerles frente. En este texto se pretende analizar esta movilización étnica como un ejemplo paradigmático de la resistencia de los pueblos originarios frente a la mercantilización de los recursos naturales; para ello se recurre al análisis de sus discursos y de los recursos de movilización empleados por este movimiento. En este trabajo se analizan las virtudes y limitaciones de la vía de la resistencia indígena frente al capitalismo verde.

Palabras clave: movimientos sociales, energías renovables, recursos naturales, pueblos originarios, despojo.

\section{Endurance winds: Indigenous movements and wind farms in the isthmus of Tehuntepec (Oaxaca, Mexico)}

Abstract: From beginnings of the year 2000, in which it began the development and implantation of wind projects in Tehuantepec's Isthmus (Oaxaca, Mexico), the indigenous peoples zapotecos and ikoots of the region they have been mobilized to face them. In this text one tries to analyze this ethnic mobilization as a paradigmatic example of the resistance of the original peoples opposite to the commercialization of the natural resources; for it one resorts to the analysis of his speeches and of the resources of mobilization used by this movement. In this work there are analyzed the virtues and limitations of the route of the indigenous resistance opposite to the green capitalism.

Keywords: Social movements, renewable energies, natural resources, original peoples, deprivation. 


\section{INTRODUCCIÓN}

"El viento no se vende, se ama y se defiende".

Proclama colectiva del movimiento anti-eólicos, Istmo de Tehuantepec, 2015.

En las últimas décadas del pasado siglo y a inicios de éste, se asiste a la irrupción de los movimientos indígenas como actores sociales y políticos del contexto latinoamericano que se están convirtiendo en sujetos activos del cambio histórico. En los países de América Latina, estos movimientos sociales se han deslizado desde el rol de actores marginales de sus escenarios nacionales hacia su conversión en agentes protagonistas de la sociedad civil. La emergencia de los movimientos indígenas ha generado importantes avances normativos en el reconocimiento de los derechos colectivos de los pueblos en los terrenos nacional e internacional. Numerosos estudios que han intentado determinar las causas de este fenómeno de "politización étnica" se han sucedido durante estos años (Stavenhagen, 1996; Gurr, 1995; Máiz, 2004).

Este artículo intenta resolver esta interrogante, a través del estudio de las variables contextuales, estratégicas y discursivas del movimiento indígena antieólico ubicado en el Istmo de Tehuantepec, al sur de México, como caso paradigmática de toda una serie de movimientos anti-neocoloniales, contra la explotación de sus recursos naturales, que se están produciendo en América Latina en la actualidad.

El escenario en los que se están produciendo estas movilización indígenas recientes nos sitúa en un momento donde el problema de la escasez de fuentes de energía fósil y el cambio climático, imponen la necesidad de realizar una transición hacia fuentes de energía renovables. Desde inicios del año 2000, en que comenzó el desarrollo e implantación de proyectos eólicos en el Istmo de Tehuantepec (Oaxaca, México) apoyados por gobiernos y empresas multinacionales, los pueblos indígenas zapotecos (binniza) y huaves (ikoots) de la región se han movilizado para hacerles frente. Para muchos, esas formas de resistencia contra-hegemónica con una expresión de democracia radical que permitiría transitar hacia nuevas relaciones sociales de producción en la era del post-petróleo.

El Istmo de Tehuantepec es la zona más angosta de México al extender en tono a los $200 \mathrm{~km}$ entre el Océano Atlántico y el Pacífico. El estado de Oaxaca, con 95,000 kilómetros cuadrados, es uno de los que cuenta con mayor diversidad del país tanto, desde el punto de vista ecológico 
como cultural. El Istmo de Tehuantepec es una de las seis regiones que conforman el estado de Oaxaca. En él habitan 580.682 personas (INEGl, 2011) pertenecientes a cinco grupos étnicos (Chontal, Mixe, Zoque, Zapoteca y Huave) además del mestizo nacional y un pequeño estrato de población afromestiza. La población zapoteca equivale al $30.5 \%$ del total; mientras que los de etnia huave representan aproximadamente un 2\% (Barabás et al, 2003).

En este trabajo se analizan las virtudes y limitaciones de la vía de la resistencia indígena frente al capitalismo verde para alcanzar un desarrollo sustentable en un espacio local concreto, dando lugar a un fenómeno glocalizado que debe definir las nuevas relaciones sociales en esta nueva fase de capitalismo avanzado post-petroleo, a partir de la aplicación de los marcos teóricos de análisis de movimientos sociales encuadrados en la "Teoría de la Movilización de Recursos".

\section{EL CONTEXTO DE OPORTUNIDAD POLÍTICA DEL MOVIMIENTO.}

Para llevar a cabo el análisis de la Estructura de Oportunidad Política (EOP) en la que se construye este movimiento, se va a recurrir, a modo de referente orientador, a los factores indicados por Tarrow (1997), Brockett y Kriesi (McAdam et al, 1999) aplicados tanto al ámbito internacional, como al nacional y local'.

Con respecto al contexto internacional, las "leyes internacionales" que amparan los derechos de los pueblos indígenas, tienen sus antecedentes en la Declaración Universal de los Derechos Humanos, de 1948. La Convención Internacional sobre la Eliminación de todas las formas de Discriminación Racial, fue adoptada por la Asamblea General en 1965. Posteriormente, el Fondo de Contribuciones Voluntarias para las Poblaciones Indígenas de las Naciones Unidas, fue establecido en 1985, con el objetivo de elaborar el Estudio del Problema de la Discriminación contra las Poblaciones Indígenas.

En 1989, la Organización Internacional del Trabajo (OIT) revisó el artículo 107 sobre "Poblaciones Indígenas y Tribales" del año 1957, y en 1989 introdujo el Convenio 169: "Convenio sobre los Pueblos Indígenas y Tribales". La celebración del el "Año Internacional de los Pueblos Indígenas" (1993) de las Naciones Unidas y la Década Internacional de los Pueblos Indígenas de ONU (1995-2004), han sido una muestra más del interés por proteger a estos pueblos.

1 Charles Tilly desarrolla el concepto de EOP para explicar que la probabilidad de que estalle un movimiento social depende de las características del contexto histórico: Grado de apertura del sistema político; grado de inestabilidad entre las elites de poder; presencia de aliados entre las elites y grado de represión de las políticas del poder. 
La reciente situación política latinoamericana también se ha caracterizado por la fuerte presencia de otros agentes internacionales como los organismos intergubernamentales y supranacionales, las agencias de cooperación transnacional y las organizaciones de desarrollo no gubernamental (Donati, 1997), que están ejerciendo su influencia sobre la vida de los movimientos indígenas en la arena política de estas naciones. Los cambios en el sistema cognitivo mundial, que coincide con la crisis de la matriz ideológica tradicional, ocasionada por el fin del periodo de "Guerra Fría", van a dar paso a una multiplicidad ideológica cuyo eje común se concentra, sobre todo, en la "ideología global" del "derecho a tener derechos" (Stavenhagen, 1996).. A la par, el nacimiento de la escuela de la "teología de la liberación", va a ser también una pieza clave en la constitución de una "Estructura de Oportunidad Ideológica"2 favorable a la construcción de los movimientos indígenas latinoamericanos.

En relación al contexto nacional, la orientación neoliberal de gobiernos como el de Salinas de Gortari se concretó en 1992 con la firma del Tratado de Libre Comercio de América del Norte (TLCAN) y con la reforma Art. 27 de la Constitución mexicana favoreciendo la privatización de las tierras ejidales y "violentando" los derechos agrarios comunitarios instaurados desde la Revolución mexicana y consagrados en la Constitución de 1917. Más tarde, en el 2000, bajo la presidencia de Ernesto Zedillo, se firma el Tratado de Libre Comercio México-Unión Europea (TLCUEM).

Todo ello tuvo su reflejo en la nueva política energética que llegó con las reformas de 2008 y $2013^{3}$. En el caso de la energía, aunque se

2 Concepto sugerido por la investigadora María Luisa Revilla, de la Universidad Complutense de Madrid.

3 La reforma en 1992 de la Ley del Servicio Público de Energía Eléctrica (LSPEE) de 1975 supuso una tímida apertura al sector privado para la generación de energía eléctrica. En 2001 se puso en marcha el Programa Sectorial de Energía 2001-2006 que se propuso desarrollar 1,000 MW de electricidad mediante fuentes renovables. La Reforma energética de 2008, impulsada bajo la presidencia de Felipe Calderón, planteó como objetivo promover la eficiencia energética, el desarrollo y utilización de energías renovables así como la inversión en las mismas. Esas líneas se profundizaron y ampliaron con la ambiciosa Reforma energética de 2013 bajo el mandato presidencial de Enrique Peña Nieto. Así, la reforma constitucional de 2013 terminó definitivamente con el monopolio estatal en la generación y comercialización de energía eléctrica así como en la exploración y extracción de combustibles fósiles. A ella siguieron en 2014 un paquete de 21 leyes y de 25 reglamentos y normativas para desarrollarlas que terminaron en 2015 con la promulgación de la Ley de Transición Energética (LTE). En el caso de la energía eléctrica es de especial alcance la Ley de la Industria Eléctrica (LIE) de 2014 que abroga la LSPEE (aunque estableciendo un periodo transitorio garantizando permisos y contratos legados), establece requerimientos de energías limpias a grandes suministradores y usuarios y supone la transición de un esquema monopolístico y monopsonio de regulación a un esquema de libre mercado basado en criterios de eficiencia económica que, junto con el desarrollo tecnológico, se considera elemento fundamental de la eficiencia energética (Martínez y Gómez, 2017). 
remarca que solo puede generarla y producirla el estado para consumo público y al precio más barato posible, se hacen modificaciones para crear fórmulas que permitan la privatización parcial de la generación de energía (no así de su distribución). Esta reforma energética se concreta en la aparición de tres modalidades de gestión privada: la "Obra Pública Financiada", el "Productor de Energía Independiente" (no está desarrollado normativamente, creando un vacío legal paralizador de este tipo de modalidad) y el "Autoabastecimiento", modalidad a la que se han acogido la mayoría de os parques eólicos del Istmo, que consiste en que un desarrollador y un gran consumidor (empresa sujeto de derecho privado) acuerdan y van al gobierno federal para pedir un permiso para crear energía y venderla a la empresa, utilizando sin embargo, la red pública para trasmitir y almacenar la energía (Nahmad et al, 2011, 2014). En el año 2006 se construye el primer parque eólico en La Venta II y desde ese año hasta la actualidad, se van a instalar en torno a 21 nuevos parques eólicos en toda la región istmeña.

Finalmente en la transición energética mexicana, los proyectos de integración regional a nivel nacional ligados a las energías renovables (Corredor eólico del Istmo) o fósiles (Corredor Transoceánico del Istmo de Tehuantepec), no se pueden entender al margen internacional, particularmente de las políticas de desarrollo regional multilateral suscritas por México. Esas políticas de corte neoliberal, donde la integración energética (gas, petróleo, electricidad) junto con la comercial tiene un peso decisivo, son alentadas por organismos financieros internacionales y están vinculadas al gran capital y a la seguridad energética donde distintos países tienen fuertes intereses económicos y estratégicos (TLCAN, Proyecto de Integración y Desarrollo de Mesoamérica, Sistema de Interconexión Eléctrica para América Central-SIEPAC).

En definitiva, en el caso del desarrollo de la energía eólica en México cabe mencionar que como fuente de generación de energía, entre 2004-2014, tuvo un incremento considerable pasando de ser inexistente a tener el $2.1 \%$ de participación, con el crecimiento medio anual más alto (100.3\%) de todas las fuentes de energía (MÉXICO, 2015b, p.72). México ha suscrito tempranamente las normas internacionales fundamentales sobre derechos de los pueblos indígenas, como el Convenio 169 de la Organización Internacional del Trabajo (OIT) donde se establece el derecho de consulta previa, libre e informada de los pueblos indígenas ante proyectos de desarrollo. Con las reformas constitucionales de 1992 y 2001 se avanzó en la inclusión de los pueblos indígenas y su condición como ciudadanos mexicanos. De forma explícita México pasó a definirse como una nación federal y multicultural. También se reconocía el derecho de autonomía de los pueblos indígenas, así como los derechos sobre sus tierras y recursos. Esos mismos planteamientos están presentes en las leyes federales sobre 
los derechos de los pueblos indígenas de $2003^{4}$ o en la Ley de Derechos de los Pueblos y Comunidades Indígenas del Estado de Oaxaca de 1998.

Sin embargo, bajo esquemas de modernización e indigenismo, la protección de los derechos de los pueblos indígenas se ha considerado secundarias respecto a las obligaciones del Estado referentes a promover el desarrollo económico de la Nación y a regular el uso de los recursos a tal fin. Es por ello que rara vez la legislación especifica claramente fórmulas para hacer efectiva ta protección de los derechos reconocidos a los pueblos indígenas.

En cuanto a la legislación energética sólo desde 2008, con la Ley para el Aprovechamiento de Energías Renovables y el Financiamiento de la Transición Energética (LAERFTE), ha hecho mención explícita a los derechos de las comunidades locales donde se instalan proyectos. Pero respecto al desarrollo de normas para proteger esos derechos 5 y la mención explícita a los pueblos indígenas eso no se produjo hasta 2014 con la Ley de la Industria Eléctrica (LIE) (Martínez y Gómez, 2017).

Respecto al contexto local, es importante señalar que en el año 1994 se inicia la fase experimental de la explotación eólica en esta región, cuyos resultados fueron similares al de otras zonas del mundo con gran potencial eólico, como Nueva Zelanda y la Patagonia argentina. Este proceso se concreta en el año 2000 con la creación de un Atlas Eólico de Oaxaca y el inicio del montaje, promoción y negociación con distintas empresas inversoras (españolas, italianas, francesas, canadienses, norteamericanas y mexicanas), la creación de parques eólicos en la zona, auspiciados por el gobierno federal, del estado de Oaxaca, el BID y USAID. Este desarrollo se produce en el marco de la Ley de Energía Eléctrica mexicana, que ha sufrido una serie de modificaciones desde los años noventa. En efecto, en 1992 se reforma el artículo 27 de la Constitución mexicana, dinamitando uno de los pilares centrales de la refundación del sistema político postrevolucionario: la inviolabilidad de la tierra y de los recursos naturales y energéticos de México, lo que impedía la privatización y compra venta de los mismos. En el periodo actual, incluso se ha abierto a la gestión privada la energía petrolífera: la "joya de la corona" mexicana (Nahmad et al, $2011,2014)$.

\footnotetext{
4 La Ley de la Comisión Nacional para el Desarrollo de los Pueblos Indígenas y la Ley General de Derechos Lingüísticos de los Pueblos Indígenas.

5 Acceso a información de los proyectos, consulta previa, contratos bajo principios de equidad y transparencia, obligación de realizar una evaluación de impacto social, sanción de prácticas corruptas.
} 


\section{MOVILIZACIÓN DE RECURSOS DEL MOVIMIENTO.}

Las movilizaciones sociales anti-eólicas de carácter étnico están presentes en el Istmo desde antes de la llegada de proyectos eólicos privados. Pero desde el 2005 en adelante, cuando comienzan a proliferar los proyectos eólicos, distintos movimientos anti-eólicos fueron surgiendo a raíz de la insatisfacción de distintas poblaciones de la región, muchas indígenas. Sin embargo, los grupos anti-eólicas, pese a un discurso no constituyen una marea homogénea. Cada uno posee intereses, estrategias y objetivos localizados como ponen de manifiesto la gran fragmentación de organizaciones existentes y las paradojas discursivas y prácticas.

Antes que nada es necesario apuntar la existencia de unos fuertes y exitosos antecedentes movilizadores en esta región durante los años 80 del pasado siglo. En efecto, en Juchitán, durante los años 70 y 80 se desarrolla un acción colectiva étnica exitosa: la COCEl6, movimiento "madrugador" de claro perfil étnico, regionalista y socialista, que obtendrá múltiples logros políticos a lo largo de su historia tales como la instauración del primer ayuntamiento popular de izquierdas de México en 1982 (Campbell, 1993,1994,1999; Rubin,1997). La COCEl emerge en un contexto político anterior a la explosión de movilizaciones indígenas en América Latina que se desarrolló en plena "Guerra Fría", en un momento de crisis del sistema político corporativista mexicano, efecto de los excesos autoritarios y represores del régimen7 (Labastida y Camou, 2001; Alcántara, 1999), dibujando una Estructura de Oportunidad Política similar al de las movilizaciones de izquierda marxista latinoamericana de esa época. Esta organización se ha caracterizado por la confluencia y articulación de cuatro bases de apoyo: los estudiantes; los campesinos; los obreros; y la comunidad vecinal- popular, y liderados por unos cuadros políticos nativos carismáticos ${ }^{8}$ destacados por su alta habilidad oratoria y su fidelidad a la tradición zapoteca.?

6 Esta organización se funda en el año 1974 con el nombre de Coalición de Campesinos y Estudiantes Juchitecos, (CCEJ), posteriormente, a raíz de la incorporación de obreros del Sindicato de Trabajadores de Oficios Varios, se transforma en Coalición de Obreros y Estudiantes de Juchitán (COCEJ) en 1975, año en que y en ese año se convierte en Coalición de Obreros, Campesinos, Estudiantes del Istmo (COCEI) (Miano, 2002:216).

7 En 1968 ocurre la matanza de Tlatelolco o Plaza de las Tres Cultural y en el 23 de septiembre de 1971 se produce otra matanza, ambas con el fin de reprimir al movimiento estudiantil. Esto agudiza la esclerosis del régimen y su profunda crisis de legitimidad y credibilidad política. En Juchitán, durante la década de los años 70 y 80 veinte coceistas pierden la vida en manos de fuerzas policiales, militares y paramilitares (Amnistía Internacional, 1986; en Campbell, 1994:26).

8 Héctor Sánchez, Daniel López Nelio y Leopoldo de Gyves de la Cruz (Campbell, 1993)

9 Este liderazgo va a estar reforzado por otro grupo de brillantes intelectuales y artistas como el reconocido pintor Francisco Toledo, Macario Matus, Víctor de la Cruz, Manuel Matus, etc quienes trabajan en tono a la "Casa de la Cultura" y a la publicación "Guchachi" Reza", y herederos de la labor del círculo intelectual de la revista "Neza" 
La COCEl se desarrolló a lo largo de una década como acción colectiva organizada, siendo su "ciclo de protesta" con momentos de "clímax" en torno a los años 1981 y 1989 (poder municipal). Su decadencia se extiende desde los años noventa, debido a la institucionalización del movimiento y a las "contradicciones y ambigüedades" entre el discurso y la praxis de sus líderes, la excesiva jerarquización interna y la exclusión de la mujer de la dirección del movimiento (Rubin, 1997: 206-236).

La COCEl como una "organización de zapotecas pobres de Juchitán"10 que consideran sus tuchas como una "continuidad de las pasadas luchas zapotecas" (Campbell, 1999). La "estructuras narrativa" principal de la COCEl gira en torno a la matriz "étnico-económica" que concilia la condición étnica y de clasell y un relato historiográfico "imaginado" (Hobsbawn, 1995; Anderson, 1993) que, junto con la vida "comunitaria", funcionan como símbolos idolatrados.

Pese a la participación activa de la mujer juchiteca en el movimiento de la COCEl, que también va a padecer la fuerte represión estatal y federal12 y la simbología construida en torno a ellas, su papel en los espacios de poder político va a ser mínimo.

Toda esta tradición movilizadora ha desembocado en una serie de referentes colectivos imaginarios comunes entre la población istmeña y zapoteca, en especial, que se podría resumir con la expresión local de que "la gente que no se deja": poseen un espíritu de rebeldía y lucha que ya forma parte de su identidad como pueblo.

Este pasado organizativo explica la proliferación de múltiples organizaciones anti-eólicos, debido a las diferentes modalidades de propiedad de la tierra (ejidal, comunal y propiedad privada), junto con la fuerte tradición política partidista (no se rige por los "usos y costumbres") y por la variedad étnica de su población (Nahmad et al, $2011,2014)$. En efecto, las organizaciones que conforman el movimiento contra la explotación abusiva de los recursos eólicos del Istmo son múltiples, junto con las alianzas y apoyos de otras organizáciones istmeñas y de personalidades relevantes de la zona, que a continuación exponemos en esta tabla:

en los años treinta (Andrés Henestrosa, Liekens y López Chiñas), la revista "Neza Chubi" de los años sesenta (Campbell,1994).

10 Juchitecos son los que "han enterrado la placenta (o ombligo)" (aunque no naciera en Juchitán) (Peterson, 1968).

11 Gestión de los recursos naturales; defensa del sistema comunal de propiedad; agricultura tradicional autosuficiente; defensa y promoción de la cultura propia; defensa de su lengua, autonomía política, derechos consuetudinarios, modelo democrático y de igualdad social ("todos somos hermanos o bichi), reciprocidad o guendalizaa y redistribución material, etc.

12 Asesinatos, detenciones, cargas violentas, desapariciones, etc 
Los "repertorios de protesta" oscilan entre las manifestaciones y marchas, las declaraciones públicas, las negociaciones con el poder 0 la rebeldía civil, el uso de las nuevas tecnologías de la información (Castells, 1999) y de los medios de comunicación de masas. En efecto, las estrategias de movilización se han conformado mediante marchas, bloqueos de carretera, manifiestos, declaraciones, actos informativos, destrucción de infraestructuras, etc, mediante los cuales consiguieron paralizar durante cuatro años la construcción del parque eólico y espantar a las entidades financieras privadas. Paralelamente, han estado permanentemente denunciando por diversos medios (manifiestos, videos, prensa, radio, etc) graves acontecimientos como los asesinatos sufridos por algunos activistas, las amenazas de muerte, los heridos de bala, la represión por parte de sicarios y paramilitares, el secuestro, las detenciones, los sobornos, las consultas amañadas e ilegítimas, etc y toda una serie de ataques represivos generados y auspiciados por el poder ${ }^{13}$. También han sido frecuentes acuerdos de empresas con autoridades estatales y federales que beneficiaban intereses de particulares ${ }^{14}$ que, en la mayoría de los casos, con ayuda de políticos y funcionarios públicos, buscaron hacerse con derechos de las tierras sin miramientos. Ese proceso estuvo marcado por la movilización de redes clientelares a todos los niveles, provocando que se manipularon las normas reguladoras de las asambleas ejidales y de bienes comunales ${ }^{15}$. Todo ello en ausencia de regulaciones claras por parte de autoridades ${ }^{16}$.

13 En el caso de Juchitán de Zaragoza, por ejemplo, el proceso de consulta inició en noviembre de 2014 y se prolongó durante meses en un clima de beligerancia entre grupos anti-eólicas y pro-eólicas generándose incluso incidentes violentos. Finalmente en votación del 30 de julio de 2015 el proyecto se aprobó por abrumadora mayoría de los asistentes (99.8\% a favor). Es de resaltar, no obstante, que, de una población municipal de más de 90.000 habitantes, sólo unas 1.300 personas (poco más del 1\%) votaron. El argumento base para la anulación del proceso de consulta fue que el correcto procedimiento se había violado, pues las licitaciones a la empresa le habían sido otorgadas por parte del Estado antes del propio proceso de consulta.

14 En un inicio, las empresas fueron convocadas por las autoridades federales y estatales y participaron en los foros al margen de las comunidades antes de las licitaciones y durante el proceso de planificación del desarrollo eólico. Una vez concertados los derechos de acceso a la red de transmisión eléctrica, las empresas hubieron de enfrentarse al problema de rentar las tierras donde iban a instalar los proyectos.

15 Convocando asambleas a las que sólo asistían miembros pro-eólicas o clientes de algún líder local, cediendo competencias de decisión en nombre de las asambleas comunitarias a representantes cooptados por autoridades y empresas.

16Sin embargo, los únicos procesos formales de consulta hasta la fecha con apego a las normas de la OIT y a la propia ley mexicana tuvieron lugar en los Municipios de El Espinal (2013) y Juchitán de Zaragoza (2014-2015) tras el "conflicto de Mareña Renovables" (2011-2014), cuando la "nueva empresa", Eólica del Sur, trasladó sus proyectos a una nueva ubicación (Martínez y Gómez, 2017). En el contexto de la aprobación de la LIE y su Reglamento en 2014, la Administración Pública en colaboración con la empresa y con la presencia de una Misión de observación independiente inició el "proceso de consulta previa, libre e informada" (con 
Quizás el hecho que mejor pone de manifiesto la ausencia de transparencia en el desarrollo eólico del Istmo es la violación del Convenio 169 de la OIT suscrito por México. El proceso de desarrollo se ha llevado a cabo sin la existencia de una consulta previa, libre e informada de las poblaciones afectadas, sean indígenas o no ${ }^{17}$. Es por ello, que la estrategia de movilización más efectiva ha sido el uso de la vía jurídica para paralizar los proyectos eólicos o exigir una consulta democrática y transparente. Ellos se han amparado sobre todo, en los artículos 18, 33 y 34 de la Declaración de NNUU sobre los Derechos de los Pueblos Indígenas; el artículo 1, 4, 5,6,7, 11, 12 y 13 del Convenio 169 de la OIT, ratificado por México, el artículo 1, 2 y 39 de la Constitución Política de los Estados Unidos de México; la Constitución Política del estado Libre y Soberano de Oaxaca y la Ley de Derechos y Culturas Indígenas del Gobierno del estado de Oaxaca, además de apelar al Alto Comisionado de NNUU para los Derechos económicos, Sociales y Culturales y al Mecanismo Independiente de Consulta e Investigación (MICI) del Banco Interamericano de Desarrollo (BID), entidad que financia algunos de los proyectos eólicos más polémicos ${ }^{18}$. No obstante,

traductores de zapoteco incluido) para cubrir los requerimientos del Convenio 169 de la OIT y la legislación nacional. Sin embargo la corrección del proceso ha quedado cuestionada, especialmente por aspectos relativos a la representatividad de los participantes y numerosas irregularidades de procedimiento. Distintas organizaciones anti-eólicas, apoyándose en los informes de la Misión de observación, y las observaciones del especialista James Anaya (2015), denunciaron diverso vicios procesales (violación del carácter libre, previo, informado y de buena fe). Finalmente 1.166 miembros y afines a grupos opositores de Juchitán interpusieron en septiembre de 2015 un recurso de amparo por violación de los correctos procedimientos del proceso de consulta que el titular del juzgado correspondiente de Salina Cruz resolvió a su favor en diciembre suspendiendo las obras de Eólica del Sur en Juchitán (Martínez y Gómez, 2017)

17 En los proyectos financiados por organismos internacionales e impulsados por las autoridades públicas mexicanas se ha aceptado como "proceso de consulta válido" las entrevistas, reuniones y "estudios de necesidades" que muchas empresas (tanto privadas como la CFE) dicen haber realizado y donde manifiestan, sin aportar prueba rigurosa alguna que lo corrobore, haber obtenido la aprobación por parte de las comunidades.Véase, por ejemplo, el Plan de Desarrollo de Poblaciones Indígenas de la CFE para el Proyecto La Venta III (CFE, 2012), parque desarrollado por Iberdrola Renovables para la CFE, dentro del Proyecto de Desarrollo de Energías Renovables a Gran Escala (PERGE) financiado por el GEF (2006-2016) con 150.35 millones de dólares.

18 Durante el desarrollo de los parques eólicos en el Istmo se presentaron ante los tribunales cientos de denuncias que no fueron procesadas o fueron desestimadas por los jueces. Se acusaba a las empresas de incumplir los términos de los acuerdos (impagos o pagos inferiores a lo acordado, imposición de restricciones no pactadas a las actividades productivas, incumplimiento de compromisos de obra pública o promesas de empleo), cláusulas abusivas (rentas injustas, derechos preferentes para la empresa para prorrogar unilateralmente derechos de usufructo de contratos a largo plazo o negociar esos derechos con terceros al margen de los usufructuarios, cláusulas de confidencialidad) y falta de transparencia en el procedimiento de consulta (falta de información con respecto a las características del proyecto, sus impactos ambientales o términos de los contratos y ganancias de la empresa). Igualmente, al menos en algunos casos como el del fallido "Proyecto Eólico San Dionisio" se ha dado cooptación y "soborno" con 
tras producirse, en febrero de 2016, un oportuno cambio de titular del juzgado, el nuevo juez, el 9 de junio del corriente, dejó sin efecto la suspensión previa y negó el amparo a los demandantes señalando que el proyecto Eólica del Sur sí fue consultado de forma previa y en apego a los parámetros legales.

Si se estima la estructura del "ciclo de protesta" del movimiento, se encuentran semejanzas con la habitual forma de la vida de los movimientos sociales. El momento de clímax del movimiento se ubica en los años 2013 y 2014, a partir de los cuales sufren una leve caída, de la que no llegan a recuperarse hasta la fecha.

\section{EL RELATO CONTRA EL ABUSO DE LA EXPLOTACIÓN EÓLICA.}

Los "procesos de enmarcamiento" se apoyan en las estructuras cognitivas y simbólicas, denominadas "paquetes de dispositivos" por Klaus Eder (1992), propias del "stock cultural" de cada colectividad (Zald, en McAdam et al, 1999). Este background cultural, configura un marco de interpretación básico y es empleado por el movimiento como un mecanismo para enmarcar la realidad de un modo "alternativo", frente a la intersubjetividad hegemónica.

Para el análisis de la "variable discursiva" se decidió analizar los "procesos enmarcadores" que aparecen en sus manifiestos. Estos procesos van a ser entendidos como esfuerzos estratégicos conscientes cuyo fin es forjar formas compartidas de considerar el mundo, que legitimen y muevan a la acción colectiva (Snow, Hunt y Benford, 1993; Gerhards, 1995).

El discurso de las organizaciones con la explotación abusiva de los recursos eólicos de la región se caracteriza por apelar a la dignidad, la autonomía, a la resistencia de su lucha, que están dispuestos a llevar al límite, y que se resume en esta frase "tenemos autonomía, tenemos vergüenza, tenemos dignidad y la defenderemos a costa de nuestra propia vida".

Más en concreto, este movimiento ciudadano e indígena anti-eólicos ha manejado tres tipos de estructuras narrativas para defender su posición: el "identitario", el "ecológico-sostenible" y el "decolonial". Finalmente, se aborda el estudio del impacto de los mismos en sus audiencias, valorando los "alineamientos y resonancias" que se originan para acabar detallando el discurso ideológico de la acción colectiva indígena y sus rendimientos, victorias y conquistas políticas.

El primer relato, que resulta el más utilizado por las organizaciones étnicas ikojts, apela a los elementos étnicos y a su posterior politización

acuerdos bajo cuerda a autoridades municipales, ejidales y de bienes comunales (Martínez y Gómez, 2017). 
de su identidad como pueblos originario, utilizando elementos propios de su cosmovisión ancestral ("atacan sus formas de vida, nuestra visión del mundo(...)somos el golpear de los cayucos llevando comida a casa"), visiones de carácter animista ("somos rayo, somos nube...somos aire del Istmo oliendo a mares") y sobrenatural ("el pueblo Ikoots es mágico...somos nahuales"), junto con el recuerdo de un pasado glorioso ("venimos costeando desde el Perú, desde los Incas desde el tiempo de nuestros ancestros"), utilizando para ello una narrativa poética y emotiva cargada de sentidos tanto para el propio pueblo ikoojs como para las audiencias extra locales que encuentran ecos con el mito del "buen salvaje". Este "marco" coloca en su médula la politización de la "identidad social" (self identity). La construcción de una "identidad política" ha resultado una de las estrategias más socorridas por los diferentes colectivos étnicos, como táctica para definir sus reivindicaciones y sus definiciones del mundo (Stavenhagen, 1997: Gurr, 1995), por ello exigente el uso de su propia fuerza soberna, autoridades (cabildo) por usos y costumbres y sus propios sistemas de seguridad mediante la creación de una policía comunitaria. Para la narrativa indígena, suele siempre existir o un tiempo pasado, una especie de pasado esplendoroso y de "edad de oro", donde estos pueblos se extendía por toda el vasto territorio que los envuelve. Posteriormente, según sus narraciones típicas, entran en un fatal declive, originado por la acción de ciertos agentes externos que los abocó a una crítica situación de "riesgo de extinción".

La segunda narración subraya la variable económica y/o de subsistencia productiva: somos campesinos y pescadores perturbados por la incompatibilidad entre estas actividades primarias tradicionales y la explotación energética eólica. Se posicionan desde un espacio económico metacapitalista ${ }^{19}$ que denuncia la mercantilización de bienes y recursos naturales que son de todos y para todos ("no pueden vender nuestro mar, nuestra tierra, nuestro viento, y nuestra propia vida"). Los indígenas conciben al universo como una gran unidad, en la que todos los elementos están vinculados y regidos por "leyes" o principios de respeto y protección, lo que les garantiza el uso sostenible de los recursos naturales necesarios para la supervivencia. Todos los entes orgánicos e inorgánicos del mundo constituyen formas de vida conscientes tuteladas por su "espíritu" o "dueño" con una actividad voluntaria animada por un alma antropomórfica, que los protege y

19 El sistema económico istmeño se caracteriza por girar en torno al mercado de la ciudad de Juchitán, -que centraliza gran parte de los productos alimentarios de la región-, en torno a un sistema de fiestas que dinamiza socioeconómicamente a la región conformando una "economía de prestigio, trueque e intercambio"; un sistema de prestigio social que no se basa en la acumulación, sino en la redistribución de riqueza través del «sistema de fiestas», a modo de potlach (Mauss, 1974). Este procedimiento garantiza la igualdad social y la inexistencia de hambre en la comunidad (Bennholdt-Thomsen, 1997). 
cuida. En algunas cosmovisiones indígenas, entre lo "cultural" y lo "natural", existe un continuun analógico. En esta "dialéctica de lo sagrado" se concibe una "antropomorfización de la naturaleza". Este segundo relato se refiere la defensa del medioambiente e intenta legitimar las acciones colectivas encaminadas a garantizar la conservación de la unidad del pueblo indígena a través del desarrollo de la conciencia etnoeconómica. Los agentes culpables de esta amenaza son las empresas multinacionales energéticas, los gobiernos regionales y nacionales y las diversas compañías que intentan explotar los recursos endógenos. De todo esto se derivan unos objetivos concretos: la búsqueda de garantías legales para el control y gestión sostenible de la zona. El marco de interpretación ambientalista "indígena" va a encontrar fuertes resonancias con el "marco ecologista" (Dobson, 1997; Dryzek, 1997; Eder, 1992) en el que se sitúan muchas organizaciones de cooperación al desarrollo, organismos internacionales, asociaciones ecologistas, intelectuales y profesionales del medio ambiente. Este master frame se genera en los años setenta, fruto de la creciente asunción de los límites ecológicos que crearon un clima pesimista que alimentó una "... nueva nostalgia de una forma de vida simple y natural y desencadenó una oleada de críticas generalizadas a la burocracia y la industrialización" (Gamson y Meyer, 1999: 396), centrándose en la calidad de vida y llegando a componer un "nuevo marco" para todos los órdenes de la vida política y social (Eder, 1992) Las perspectivas ecologistas van a utilizar como modelos ideales de referencia a las "formas de vida" típicas de las comunidades indígenas ${ }^{20}$.

Por último, la tercera estructura narrativa se apoyo en los postulados decoloniales con el fin de denunciar la nueva colonialismo y conquista por parte de agentes ajenos a los intereses del pueblo ("estamos en una tapa de reconquista....nos dan espejitos por oro"). Este "despojo" y la pérdida de soberanía deriva de un nuevo neocolonialismo y denunciando las nuevas formas del capitalismo neocolonial de "acumulación por desposesión" (Harvey, Duarte Pozas y Jiménez Maya) (Nahmad et al, 2011, 2014). Las causas que han arrastrado a este escenario son consideradas por ellos como el producto de las fuertes agresiones externas que ha recibido este pueblo a to largo de la historia. Desde el punto de vista de la percepción política indígena, la escasa ética en las prácticas depredadoras, devastadoras e ilegales de estos "agentes", los convierte en los principales responsables y culpables del desequilibrio ambiental que puede conducir al exterminio y desaparición de este pueblo. El objetivo, por tanto, es garantizar la reproducción y supervivencia del pueblo indígena a través de la puesta en marcha de políticas públicas que garanticen dos elementos básicos: el reconocimiento y respeto de su territorialidad a través de la gestión y

20 Esto se refleja en los análisis del denominado "paquete fundamentalista" ,descrito por Klaus Eder para caracterizar los movimientos ecologistas en Europa (1992:18). 
control del uso de sus tierras. Consideran que los movimientos indígenas no pueden reducir su lucha a cuestiones localistas, pues forman parte de la actual estructura económica y sociopolítica global (Sánchez, 1999), la interacción global-local se presenta como inevitable. La mayor parte de las empresas implicadas en el desarrollo del Corredor Eólico del Istmo son multinacionales extranjeras que actúan bien como fabricantes de aerogeneradores y sus componentes, desarrolladores de proyectos e instalación u operadores de los parques eólicos. Aunque las multinacionales españolas tienen presencia destacada en el desarrollo eólico mexicano y algunas (Iberdrola, Acciona) un papel sobresaliente en el sector eléctrico mexicano, la gran movilidad de capitales en el sector energético así como la red cambiante de filiales de empresas hace que la identidad de los inversores y empresas participantes sea mucho más amplia. Por otra parte, la mayoría de las concesiones de parques eólicos corresponde a la modalidad de Autoabastecimiento . Eso significa que los consumidores a los que va destinada la generación de energía son grandes empresas nacionales o multinacionales con sede en México ${ }^{21}$. En estos discursos, los indígenas identifican a un único "actor público": la humanidad, todos los seres humanos excluidos, marginados e invisibilizados por el proceso de globalización o neoliberal.

Para que un "proceso de enmarcamiento" sea eficaz y consiga el éxito proyectado por el actor social, es necesario que se generen "alineamientos" y "resonancias" con las "audiencias" a las que, explícita e implícitamente, va destinado (Snow et al, 1993; Gamson,1999). Si analizamos los "marcos interpretativos" y las organizaciones mentales por la cual los movimientos indígenas definen su situación, se observa que han articulado un nuevo discurso político que persigue crear o recrear la autoestima de los grupos de estatus minoritarios mediante la afirmación de su identidad colectiva. El papel de las comunidades y de su movimiento social, debe ser protagónico en la resolución de todos estos graves conflictos que están poniendo en peligro su subsistencia como civilización, pues además de considerarse los más cualificados para garantizar el mantenimiento de la riqueza ecológica de este medio ambiente, son los que pueden preservar la infinita riqueza de su saber ancestral y milenario, algo que beneficiaría al patrimonio natural y cultural del conjunto de la humanidad. Este "marco" se dirige

21 El negocio eólico es un gran negocio para las empresas multinacionales, tanto para las generadoras de energía como para sus clientes que son grandes consumidores. Las empresas privadas generadoras de energía gozan de diversos incentivos fiscales (esquemas de depreciación acelerada de equipo con impacto ambiental favorable, arancel cero), contratos de suministro con la CFE asegurados a largo plazo (20 años o más), banco virtual de energía, acceso a financiación de organismos internacionales, ganancias resultado de operar en los mercados de carbono. Los grandes consumidores asociados bajo el esquema de autoabastecimiento a su vez obtienen precios de energía con tarifas más bajas que las de consumidores del sector residencial o pequeños consumidores del sector industrial, comercial y servicios. 
especialmente a tres "audiencias": la población istmeña; el pueblo mexicano y sus autoridades y, por último, el "auditorio" más importante: las organizaciones internacionales y supranacionales. Estos nuevos actores sociales internacionales van a estar insertos en los polos ideológicos "culturalistas" y "postmaterialistas", que están interviniendo como constructores de las "solidaridades internacionales", que reúne los "iconos políticos" anticoloniales, con los nuevos discursos democratizadores, de respeto a los derechos humanos y de apoyo a las minorías excluidas y marginadas, y que apoyaran la causa indígena por sus componentes de identidad, etnicidad, ecologismo y defensa de los derechos de una minoría desfavorecida. El impacto de este "marco" en estas tres audiencias, va a conformar una importante parte de la eficacia y el éxito de la movilización indígena.

Las características del sistema político latinoamericano, con una democracia liberal frágil resultado de una transición autoritaria de "pactos entre elites", minimizan el componente participativo de la "sociedad civil" en la vida pública del país (Alcántara, 1999). Las orientaciones de la "opinión pública" no disfrutan del mismo peso político que en los sistemas democráticos más consolidados, por lo que los debates que se generan en ella, no originan efectos en las dinámicas políticas del gobierno, lo que desemboca en un agrietamiento entre el sistema político y la sociedad, multiplicando un panorama democrático inestable y precario, con fuertes crisis de "gobernabilidad".

Los pueblos indígenas, al igual que el resto de los movimientos étnicos, han estado combatiendo por conseguir el ingreso en el espacio político y por su reconocimiento como "sujetos sociales modernos", representantes de nuevos intereses colectivos, reivindicando con orgullo la figura del indígena, que nunca estuvo incluida en el imaginario patrio y en la identidad nacional.

\section{CONCLUSIONES}

Desde una perspectiva cosmopolita y en un contexto de cambio climático y crisis del petróleo, la apuesta por las energías renovables debería ser una prioridad impulsada por todos tos gobiernos y actores públicos internacionales en el mundo, con el fin de conseguir realizar la llamada "transición energética y apostar por un futuro más sostenible y respetuoso con el medio ambiente. Pero en un momento de glocalización, ¿̇qué ocurre cuando estas tendencias globales se asientan en espacios concretos con fuertes hechos culturales diferenciales y tradiciones étnicas prehispánicas? ¿qué pasa cuando se produce un injusto sistema de reparto de los beneficios de la explotación energética y los habitantes locales son excluidos, ignorados, 
engañados, desinformados y no consultados, y por tanto, los más perjudicados?

El movimiento antieólicos ha conseguido una serie de victorias colectivas y ciudadanas, como el refuerzo de las identidades étnicas, democratización y transparencia del proceso, la paralización de obras y la progresiva mejora de contratos y condiciones de negociación, pero aún queda un largo camino para que se integren medidas de desarrollo comunitarios, tanto por parte el gobierno como de las empresas, a través de la responsabilidad corporativa ambiental y social

Es importante destacar que una de las grandes victorias que esta movilización antieólica obtuvo fue la paralización por la vía jurídica de la construcción de un parque eólico de "Mareñas Renovables" en esta región. En efecto, el 11 de diciembre de 2015, el juez séptimo de distrito de Salina Cruz, Isaías Corona Coronado otorgo la suspensión definitiva a favor de los 1165 integrantes del pueblo zapotecos o binniza, que interpusieron un amparo por las violaciones al derecho de los pueblos indígenas a ser informados, consultados, para otorgar o negar el consentimiento respecto a la instalación de cualquier proyecto de infraestructura en nuestro territorio, apelando al Convenio 169 de la OlT, siendo la primera vez que se hace efectivo la apelación a este convenio internacional, -ratificado por el gobierno mexicano-, para proteger los derechos e intereses de los pueblos indígenas en México. En 1989, la Organización Internacional del Trabajo (OIT) revisó el artículo 107 sobre Poblaciones Indígenas y Tribales del año 1957, y en 1989 introdujo el Convenio 169: Convenio sobre los Pueblos Indígenas y Tribales (Sánchez, 1999). Anteriormente a estos dos convenios, la OIT había realizado en 1953 un estudio denominado Pueblos indígenas: condiciones de vida y de trabajo de la población aborigen en los países independientes. El Convenio 169 fue aprobado por la Conferencia General de la OIT en ese mismo año y ratificado por un número considerable de países. Este documento fue el primer instrumento internacional que explícitamente descartó el enfoque integracionista que ha sustentado las políticas de los gobiernos durante deceníos. Este convenio Trata un significativo número de derechos de las etnias indígenas: la tierra, condiciones de empleo, salud educación, participación y consulta, además del establecimiento de obligaciones de los gobiernos hacia estos pueblos. Posteriormente, en el mes de febrero de 2016 cambian at titular del juzgado séptimo de distrito, llegando a la región una persona con poca disposición, conocimiento de los derechos de pueblos indígenas además de una clara intencionalidad de beneficiar a las empresas multinacionales.

Si bien es cierto que el movimiento social antieólicos no es homogéneo ni siquiera persigue exactamente los mismos objetivos políticos, la aplicación de una "justicia energética" que atienda a un reparto democrático y redistributivo de los beneficios de la explotación de las energías renovables, cuyos proyectos pueden ser compatibles con otras 
actividades económicas primarias, es fundamental entre la población del Istmo de Tehuantepec. Esta región es la tercera en el mundo en potencialidad eólica y esto debiera obligar al gobierno mexicano y a los organismos financieros internacionales a tratar con sumo cuidado la defensa de los derechos e intereses de su población, frente a las lógicas del capital extranjero de maximizar sus beneficios con el mínimo de costes monetarios.

\section{BIBLIOGRAFÍA}

Alcántara, M. (1999): Sistemas políticos de América Latina. México, América Central y el Caribe. Vol II. Madrid. Tecnos.

Anderson, B.(1983): Comunidades imaginadas: reflexión sobre el origen y difusión del nacionalismo. FCE. México.

Barabás, A.; Bartolomé, M.; Maldonado,B. (2003): Los pueblos indígenas de Oaxaca: atlas etnográfico. México DF. FCE. CONACULTA-INAH.

Bennholdt-Thomsen, V. (1994): Juchitán, la ciudad de las mujeres. Instituto Oaxaqueño e las Culturas. Fondo Estatal para la Cultura y las Artes. México.

Campbell, H., y Green, S. (1999): Historia de las representaciones de la mujer zapoteca del Istmo de Tehuantepec, en "Estudios sobre las culturas contemporaneas", época IIV, Num.9, Colima, junio (pag.89-112)

Campbell, H.; Binford, L.; Bartolomé, M.; Barabás, A. (edit) (1993): Zapotec struggles: histories, politics and representation from Juchitán (Oaxaca).Smithsonian Institution Press. Washington And London.

Campbell, H.(1989): La COCEl: cultura y etnicidad politizadas en el Istmo de Tehuantepec, en "RevistaMexicana de Sociología, año LI, num 2 , México, abril-junio.

CONAE, 2003. Guía de gestiones para implementar una planta de generación eléctrica que utiliza energía renovable en México. CONAE, México. 77 pp.

Covarrubias, M. (1946): El Sur de México, INI, México.

Dobson, A. (1997): Pensamiento político verde... Paídós. Madrid

Dryzek, J. (1997):The politics of the earth: environmental discourses. Oxford University Press. United States

Eder, K. (1992): Framing and Communicating Environmental Issues. A Discourse Analysis of Environmentalism. European University Institute. Florence 
Gerhards, J. (1995): Framing dimensions and framing strategies: contrasting ideal-and real-type frames.London. Social science Information.

Gómez, Á. (2003): Movilizaciones indígenas en las selva húmeda tropical latinoamericana: Ios Tawahas. México DF. Plza y Valdés.

Goffman, E. (1974): Frame analysis. Cambrigde. Harvard University Press

Gurr, T. R. (1995): Minorities at risk: a global view of ethnopolitical conflicts. Washington, D. C. United States Institute of Peace Press.

Hobsbawn, E. (1995): Naciones y nacionalismo desde 1780. Barcelona. Crítica.

Labastida, J. y Camou, A. (coords)(2001): Globalización, identidad y democracia: México y América Latina. México DF. Siglo XXI.

Máiz, R. (2004): El indigenismo político en América Latina, en "Revista de Estudios Políticos", No 123, Enero-Marzo. Centro de Estudios Políticos y Constitucionales. Madrid.

Martínez González, Miguel; Gómez Suárez, Agueda (2017): Vientos del capitalismo verde: glocalización, desarrollo y transición energética en el Istmo de Tehuantepec (Oaxaca, México), en "Revista Ciencia y trópico" . Brasil (inédito)

McAdams, D., McCarthy, J, Zald, M (comp): (1999): Movimientos sociales: perspectiva comparada. Madrid. Itsmo.

Miano, M. (2002): Hombre, mujer y muxe' en el Istmo de Tehuantepec. Plaza y Valdés. CONACULTAINAH.México.

Nahmad, Abraham (2010), "Introducción", en Nahmad, Salomón, Margarita Dalton y Abraham Nahón (coords.), Aproximaciones a la región de Istmo. Diversidad Multiétnica y socioeconómica en una región estratégica para el país. Publicaciones de la Casa Chata, CIESAS, 2010. México, D.F.

Nahmad y otros, NREL. 2004. Atlas de Recursos Eólicos del Estado de Oaxaca, elaborado por el grupo de recursos eólicos del Laboratorio Nacional de Energía Renovable (NREL), No. NREL/ TP-500-35575.

Newbold Chiña, B. (1975): Mujeres de San Juan. La mujer zapoteca del Istmo en la economía. SEP, México.

Newbold Chiña, B. (1992): The Isthmus Zapotecs. A matrifocal Cultural of México. California StateUniversity, Chico.

Peterson, A. (1990): Prestigio y afiliación en una comunidad urbana: Juchitán, Oaxaca. Tr. Carlos Guerrero. México : INI - CNCA.

Rubin, J. W. (1997): Decentering the Regime. Etnicity, radicalismo and democracy in Juchitán, México.Duke University Press. 
Sánchez, C. (1999): Los pueblos indígenas: del indigenismo a la autonomía. México. Siglo XXI.

Smith. A. (2000): Nacionalismo y modernidad. Istmo. Madrid.

Snow, Hunt y Benford (1993): Framing proceses and identity construction in collective action. Chicago.Presented at the Annual Meetings of the Midwest Sociological Society.

Stavenhagen, R. (1996): Ethnic conflicts and the Nation-State. New York. UNRISD.

Tarrow, S. (1997): El poder del movimiento. Los movimientos sociales, la acción colectiva y la política. México DF. Alianza Editorial.

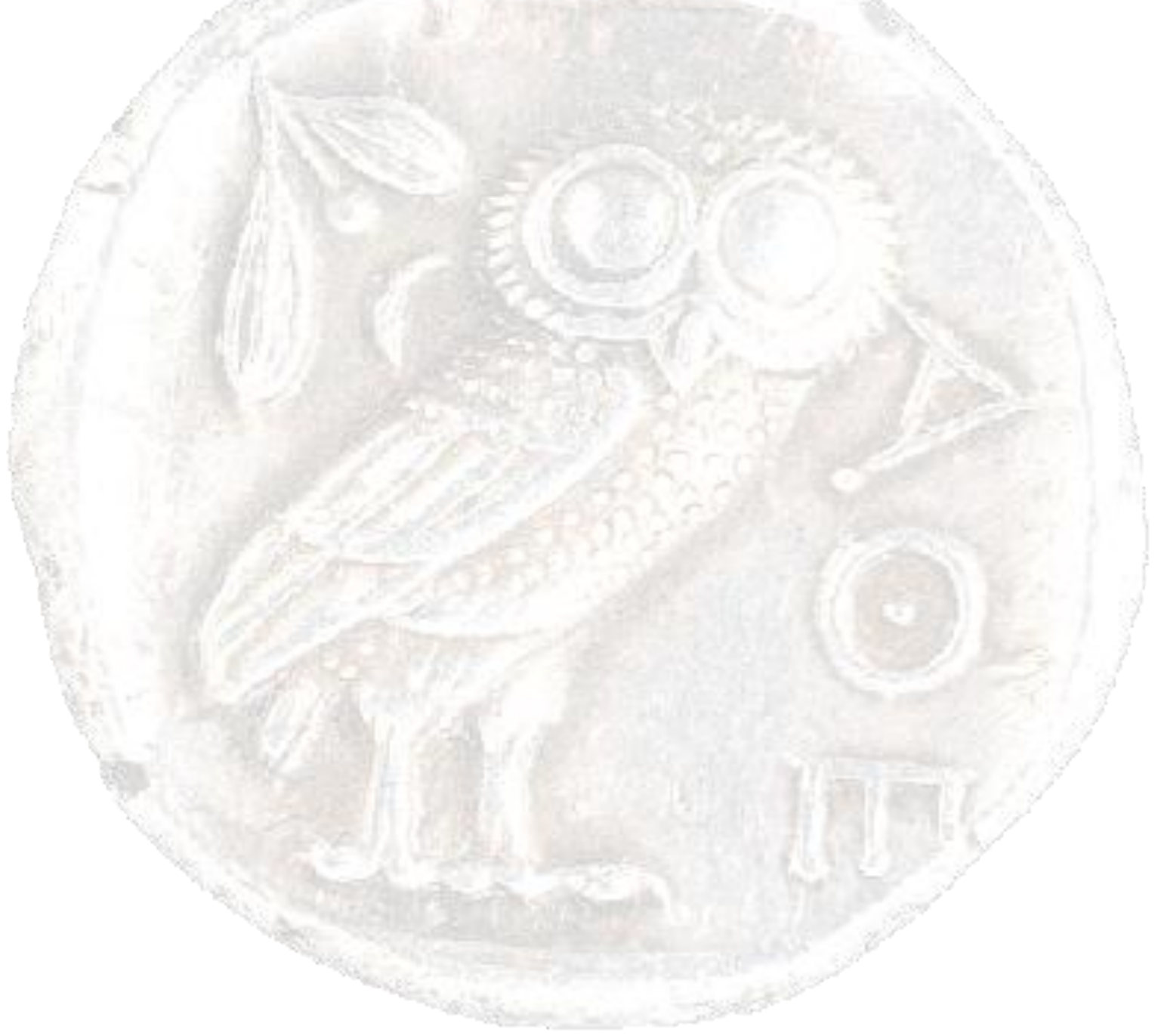

